\title{
Information use in strategic decision making
}

\author{
Johan Frishammar, School of Business \& Engineering, Halmstad University, Halmstad, Sweden
}

\begin{abstract}
This paper addresses the issue of information use in strategic decision making. The study employs a case study as a research strategy together with personal interviews and documentation as means of data collection. The starting-point is four specific strategic decisions recently made by medium-sized companies in Sweden. The study provides the reader with an insight into management information behaviour when taking strategic decisions, by addressing questions such as: Why is information used? What kind of information does management use? How do they obtain it? And finally, where do they obtain it? In addition, a short review of the literature pertaining to the above stated questions is provided.
\end{abstract}

\section{Introduction}

What is the foundation underlying organizational decision making? This question is crucial since decisions, especially those of a strategic nature, tend to have widespread effects on organizational members, processes, and structure. This paper is concerned with one foundation of strategic decision making: the acquisition and use of information. In other words, our aim is to take a closer look at the information-gathering behaviour that underpins strategic decisions. More specifically, we aim to empirically address the why?, what?, how? and where? of this process. Thus, we conceive a firm's external environment to be a source of information (Aldrich and Mindlin, 1978) but also its internal environment, sometimes referred to as invironment. To scan the environment in order to make better-informed decisions (Choo, 1996) is an important task on the corporate agenda. Environmental scanning, whether or not it is referred to as such (Frishammar, 2002), may be defined as "the activity of acquiring information" (Aguilar, 1967, p. 1) and is the method by which managers perceive events and trends (Hambrick, 1982). Acquiring information is imperative in ascertaining environmental change and has implications for strategic decision making (Lozada and Calantone, 1997). In this study, strategic decisions are concerned with long-term direction and are normally about trying to achieve some advantage for an organization (Johnson and Scholes, 1999). A decision is, in accordance with Mintzberg et al. (1976), defined as a set of actions and dynamic factors beginning with the identification of a stimulus for action and ending with a specific commitment to action. Strategic simply means important, in terms of the actions taken, the resources committed, or the precedents set (Mintzberg et al., 1976). Further, these decisions concern choices about issues that materially affect the survival prospects, well being and nature of the organization (Schoemaker, 1993). In this paper, where strategic decisions are studied retrospectively, we assume a rational/traditional perspective on strategic decision making (Hendry, 2000) in contrast with the interpretative view (see Laroche (1995)). More specifically, we aim to empirically address the following questions:

* Why is information used in strategic decision making?

* What kind of information is used in strategic decision making?

* How do decision makers obtain the information used?

* Where do decision makers obtain the information used?

Testing these questions empirically is justifiable, since comparable studies are often out-dated, made in other space-time chunks. Combining the questions into a single study was also considered to provide insight and add to the existing body of knowledge. In order to clarify, the aim here is not to study entire decision-making processes, but to study information[1] acquisition and use. Such activities must precede strategy formulation and decision making (Fahey and Narayanan, 1986). The next section of the paper, comprising the frame of reference, is intended to expand and further elaborate on these questions.

\section{Frame of reference}

Why is information used in strategic decision making? In organization science, it seems to be widely accepted that the purpose of information use is to reduce or remove uncertainty. Uncertainty could be defined as the difference between the information processed and the information required to complete a task (Tushman and Nadler, 1978; Kaye, 1995) or as an inability to 
predict accurately what the outcomes of a decision might be (Duncan, 1972). In a classic study, Milliken (1987) made a distinction between state, effect and response uncertainty. In the case of state uncertainty, administrators lack information about the nature of the environment. With effect uncertainty, the shortage of information is in knowledge of how environmental events or changes will affect the particular organization. Finally, in the case of response uncertainty, there is a perceived lack of information about what the organization's response options are and/or the value or utility of each course of action (Milliken, 1987).

What kind of information is used in strategic decision making? Information may be classified as soft or hard. Soft information consists of images, visions, ideas and cognitive structures. Further, soft information can also consist of multiple conceptual schemes in the form of frames of reference or worldviews (Häckner, 1988). Gossip and hearsay are also examples of soft information (Mintzberg, 1975). Soft information is tied to an individual person, and may be characterized as broad, general and subjective. In contrast, hard information is or can easily be quantified and processed with the help of analytical methods. Such information is generally expressed numerically and is operationalized and defined as numerical information generated, used, or reported in companies' financial accounting and control systems, calculation systems, cost accounting systems, production control systems and statistics from various sources (Häckner, 1988). The findings of Häckner (1988) indicate that different kinds of decision-making situations may call for different kinds of information, but usually one type of information is almost always combined at least to a limited degree with the other type.

How do decision makers obtain information? Starting with that of Aguilar (1967), previous research has shown that information may be obtained on a solicited or unsolicited basis. Solicited information includes, first, all information explicitly sought by managers (explicitly solicited), but also second, information given to managers because of organizational requirements (organizationally solicited). Unsolicited information includes all information that cannot be classified under the above categories. This information may be classified as either directed (intentional and purposeful on the part of the source) or undirected communications (Aguilar, 1967).

Where do decision makers obtain information? Earlier findings indicate that executives and/or decision makers use different information modes to learn about the environment (Aguilar, 1967; Daft et al., 1988). The distinction made is between external and internal sources of information. An external source originates outside the boundaries of an organization, while an internal source originates within an organization. These sources may, in turn, be further divided into personal and impersonal sources. Personal sources refer to direct human contact, while impersonal sources are written/non-verbal in nature (Daft et al., 1988). Aguilar (1967) found that, for important external information, managers tend to rely almost as much on inside sources as on outside sources. In later studies, too, the results with regard to this question have been mixed (see Elenkov (1997) and Ghoshal (1988)). Personal sources, however, far exceeded impersonal sources in importance in the study of Aguilar (1967). This result is supported by Keegan (1974) and Thomas (1980), who found personal sources consistent with the informal, irregular scanning that typifies many organizations.

\section{Method and approach}

The research strategy used was case studies. The cases studied are strategic decisions made in four companies. We could not study all decisions - that would be too costly - although we could not manage with one either - due to what Galtung (1967) calls the le cas pur problem: the problem of finding the ideal case. Therefore we took some, i.e. four. All companies whose decisions are studied are located in Sweden and are briefly described below; the last three are listed on the OM/Stockholm stock exchange:

1. Alpha, a subcontractor to the heavy vehicle industry performing such activities as tool manufacturing, pressing, cutting, and surface treatment. The company had around 300 employees and the decision taken concerned buying another company with 50 employees. The reasons behind the purchase were to achieve economies of scale in production, computer systems and R\&D. Moreover, the decision was perceived as a diversification response since the acquired company was active in another market niche, specialized in long series employing automated production techniques. Finally, to expand in terms of volume was seen as necessary for long-term survival in the industry.

2. Beta, a company specializing in information logistics, graphic solutions and office supplies. The company had approximately 1,900 employees and the decision taken concerned buying a division with approximately 40 employees from a major corporation. Motives for buying were to strengthen the relationship with the selling company (an important customer) as well as to obtain a second production site situated in a different geographic area. Moreover, Beta had a deliberate wish for expansion within the area of information logistics.

3. Delta, a company focused on development, manufacturing and R\&D in environmentally friendly products. The company had approximately 350 employees and the decision studied concerned selling off one of its divisions, which employed 50 persons. Motives behind the sale were that the division was not focused on environmentally friendly products, and did not 
share customers or technology with other divisions in Delta. Furthermore, the division faced fierce competition and was in need of increased economies of scale in purchasing and marketing, which constituted a large part of total costs. In addition, the sale generated funds for planned acquisitions. Finally, the division turned profits into losses for the period 2001, a further motive mentioned by management.

4. Gamma, a research-intensive firm active in the biotech sector. The company had approximately 300 employees and the decision studied concerned selling one of the two divisions constituting operations, employing 150 persons. Motives for the sale were a perceived lack of strategic fit between the two divisions, which meant that no synergies could be obtained. The division sold was also considered inferior in comparison with its competitors in terms of size, market share, and technology. Cultural differences between the two divisions as well as the need to strengthen the company's financial position were also mentioned as important reasons for this decision.

Analytical criteria for sampling were that companies were: medium-sized in terms of employees; had taken and implemented a strategic decision during the year 2001; and were active in different industries. Several interviews lasting between 45 minutes and two hours were conducted at each company in order to allow for an accurate description of the decisions, thus comprising the empirical body of the study. All in all, 19 interviews took place at four companies: 17 interviews were conducted to address the research questions, and two provided valuable background information. The decision-making team at each company was identified by means of a snowball technique, asking each respondent who the other actors were. Each interview was recorded and included in a case-study protocol for each firm (Yin, 1994). To ensure construct validity, documentation in the form of annual reports, press releases, newspaper clippings and overhead materials was used to augment the interview data. As in most case studies, the sample size is limited and external validity questionable. Therefore, due to potential fallacies, no attempt has been made to generalize beyond the sample. The study is built around a limited non-probability sample and, hence, the results should be viewed more as hypothetical for what we might expect to find in other decisions than true for decisions universally. Unfortunately, no records of these decisions could be found, a problem also encountered by Mintzberg et al. (1976, p. 248), who stated that "Investigation of records is often impossible because strategic decision processes seldom leave reliable traces in the files of the organization".

\section{Results}

With regard to the first research question (Why is information used in strategic decision making?), it can be said that information is used for the purpose of reducing or removing uncertainty, as defined by Duncan (1972) and Kaye (1995). This fact is stated by a majority of actors in all four firms. Different actors use different terms to describe this, for example, risk reduction, identification of opportunities and threats etc. but they all seem to refer to the same concept[2], which is uncertainty. A summary of data for RQ1-3 can be found in Table I.

Judging from the empirical observations, it seems that the decisions made by Alpha and Beta were associated with greater effect uncertainty than the ones made by Delta and Gamma. The uncertainty reported by respondents was, however, nonexistent, low or moderate in all decisions. In Alpha, uncertainty was of both state and effect character. The reasons for this uncertainty were a lack of funds for the acquisition, value of stock and inventories, the fear that management would lose focus after the acquisition, and the fact that the acquired company was bankrupt. In Beta, all uncertainty experienced was of effect character; the decision taken was seen as potentially harmful to an existing relation with a major customer. Moreover, some of the other actors bidding for the division that Beta bought were customers of Beta, something that created uncertainty. In Delta, none of the respondents experienced any uncertainty whatsoever. In Gamma, the uncertainty experienced was mainly of effect character; a division was sold before important partnerships had been established, and the reaction of the stock market could not be fully anticipated.

With regard to the second research question (What kind of information is used in strategic decision making?), a classification into hard and soft information was adopted. In Alpha, decision makers tended to rely on soft information on average. In Beta, Delta and Gamma, hard information dominated on average. It should be stated, though, that all companies used a combination of soft and hard information, even if some individual respondents relied exclusively on either one or the other. Worth noting is that, independent of company or specific decision taken, the combination of soft and hard information seemed to vary over time. A majority of respondents indicated that, at the beginning of a process, soft information predominates. Most respondents start out with soft information (visions, ideas, cognitive structures, etc.), and then move to hard/numerical information as the process unfolds. The picture provided by respondents is that soft information serves as a base for interpreting which hard information is relevant and which is not. At that stage hard information becomes more important, leading to the application of analytical methods for studying figures. At the end of the process, however, many respondents returned to soft information again. As indicated by a majority of the respondents, it is impossible to "count all the way". At the time when the actual decision is taken (i.e. strategic choice), intuition, cognitive structures etc. again come into play. 
With regard to the third research question (How do decision makers obtain the information used?), a classification into solicited and unsolicited information was used, based on the findings of Aguilar (1967). The results show that all companies tend to rely heavily on information received on a solicited basis. In Alpha, Beta and Gamma, the bulk of the solicited information was explicitly solicited, while organizationally solicited information dominated in Delta. In all companies, information classified as unsolicited was less frequently used, although it was nevertheless recognized as very important. In all companies, information classified as unsolicited was more undirected than directed. These findings run contrary to Aguilar's (1967) finding that a majority of the information was received on an unsolicited basis. Aguilar also found that organizationally solicited information was more important than that explicitly solicited and that directed unsolicited information was more important than undirected unsolicited information.

The fourth research question (Where do decision makers obtain the information used?) was addressed by making a distinction between external and internal sources, further divided as personal and impersonal sources. A summary of data for RQ4 is contained in Table II. The results show that Alpha and Beta both rank their customers as the most important source of information. Moreover, the top-three ranked sources in both companies are personal sources. In Delta and Gamma, performance reports (impersonal in nature) were deemed the most important source of information. Overall, our data show a pattern where internal sources of information seem to be preferred over external ones, Alpha being an exception. For the whole sample, four of the five most important sources are internal, a finding in line with that of Ghoshal (1988). Again for the whole sample, the two sources perceived as most important are personal: subordinates and customers, a finding in line with that of Aguilar (1967), Sawyerr et al. (2000) and others. Also worth noting is that many sources of information received low or very low values.

\section{Discussion}

Here, we shall allow ourselves to be a little bit more speculative, trying to provide theoretical as well as empirical suggestions on how our results can be interpreted. First, the experience of no, low or moderate uncertainty in these strategic decisions may have several explanations. First, if other options are few or non-existent, the experience of uncertainty may be lower, as would seem to be the case in the decisions of Delta and Gamma. Another explanation may be that of bounded rationality (March and Simon, 1958; Cyert and March, 1963). A limited conceptualisation of problems does not require extensive knowledge or omniscience. Instead, cognitive heuristics and simplifying knowledge structures may reduce information processing demands. This explanation has previously shown itself to be applicable to strategic decision making (Dutton and Jackson, 1987).

A low degree of experienced uncertainty may also be due to expertise within an area, termed as an "expert model" for the processing of information by Lord and Maher (1990). Being an expert in a specific content domain would allow management to rely on existing knowledge structures to supplement simplified means of processing information. Thus, "uncertainty may be as much a function of the expertise of the decision maker as it is a function of a particular decision context" (Lord and Maher, 1990, p. 20). Finally, a low or non-existing degree of uncertainty might be due to retrospective rationalizations of prior actions. Managers may, in the words of Weick $(1995$, p. 11), "render that outcome sensible by constructing a plausible story that produced it", i.e. an interpretation that makes good sense.

Multiple explanations for the combination of hard and soft information are possible. First, the nature of the decision might play a role. Earlier research suggests that offensive decisions (i.e. build-up of capacity/market expansion) are associated with the use of soft information. The opposite, defensive decisions (i.e. reduction of capacity/market withdrawal), were associated with hard information (Häckner, 1988). The decisions of Alpha and Beta could be classified as offensive, while the ones of Delta and Gamma could be classified as defensive. This suggestion would, however, single out Beta as being an anomaly. Second, some respondents have indicated that they rely more on soft information, thus letting their employees "do the counting". Galbraith (1973) noted that organizations must process more information as their tasks increase in complexity, which might be the result following a strategic decision, at least when acquiring a division or company. Increased information-processing needs may result in hierarchical overload, which can be solved by letting other employees process hard information, i.e. division of labour. The specific combination may also be affected by an individual's decision-making style. Some may feel more confident with hard information and others with soft. A few respondents have indicated that they can use hard information as a substitute for soft information and vice versa, depending on what is available. This explanation might be plausible in cases where a decision is taken under strong time-pressure, which was the case in Alpha. Another factor that might affect the combination is if the decision is perceived as very clear, which was the case in Beta. Then it might be possible to rely more on hard information. Still another possibility is that the combination of soft and hard information is influenced by managers' assumptions about the environment. If managers perceive the environment to be unanalysable, soft, qualitative information combined with judgement and intuition may play a major role in interpretation processes. The opposite might 
prove true if managers assume the environment to be analysable (see Weick, 2001, pp. $245 \mathrm{ff}$.). Finally, a clear majority in all companies were of the opinion that the combination of hard and soft information is contingent on the specific decision taken. This is logical, since information has no intrinsic value. Its value depends upon its context and its utilization by particular users on specific occasions, and the value of information to its users may be impossible to determine in advance (Eaton and Bawden, 1991).

Multiple reasons may also lie behind the specific combination of solicited and unsolicited information. First, the tendency to rely heavily on solicited information might be an effect of the hierarchical level. As managers' time is limited, information may be requested (org. solicited) as well as sought (exp. solicited). The use of solicited information in preference to unsolicited may also depend on whether the "case" is straightforward or unclear/complicated. Having a good overview of the process may decrease the need for unsolicited information, which might be the case with Beta. However, several companies described unsolicited information as very important. Therefore, volume may not tell the whole story. To use a metaphor, yeast is very important when baking bread, although less used than flour in terms of volume. In some cases, the preference for organizationally solicited information may stem from the fact that the individual has only been with the company for a short time, and is thus more dependent on other actors for information. On the other hand, the use of explicitly solicited information over organizationally solicited information may be the result of poor horizontal communication within the management team. A heavy emphasis on line communication may increase the need of individual respondents to find the information they require themselves.

How should the results about source utilization be interpreted? As noted by Daft et al. (1988), personal sources may be needed to interpret unclear issues. An enquirer may prefer to seek information from an individual perceived to be reliable, since the latter can supply not merely the facts required, but also advice, guidance, and encouragement (Kaye, 1995). This may be the case in the decisions of Alpha and Beta, pointing to the importance of customers as information source. It is tempting to claim that information from personal sources is soft in nature, but this may be taking the data one step too far. It should also be noted that impersonal sources may be appropriate when environmental events are discrete and analysable, which may be the case in the decisions of Delta and Gamma. Again, it is tempting to suggest that performance reports contain only hard information, but this is difficult to state with accuracy. Overall, the fact that internal sources are considered more important than external ones may be viewed in light of the findings of Sawyerr et al. (2000); the author noted a positive relationship between perceived source accessibility and frequency of usage. The fact that several sources have been given low or very low values may be due to the fact that scanning is costly and information is boundless. In practice, organizations can only cope with a small fraction of the information that keeps pouring in.

\section{Implications for management and academia}

As noted by Yin (1994), interviews should always be considered as nothing more than verbal reports. As such, they are subject to the common problem of bias, poor recall, and poor or inaccurate articulation. Although augmented by documentation, setting out policy recommendations based on a qualitative, descriptive study with a limited sample size is awkward. Only four firms/decisions were studied, and results and implications should be interpreted with that in mind. Some issues will, however, be commented upon. First, strategic decisions similar to those studied here are likely to be uncertain in nature. Therefore, it might be useful to practise some out-of-the-box thinking, in order to obtain a realistic perspective on them. In terms of information use, a combination of soft and hard may be fruitful. Exclusive reliance on soft information could endanger the quality of the decision and distance it from reality. The opposite, a reliance on hard information only, may lead to difficulties in reaching a decision in the first place. In terms of information sources, it is difficult to say if any given source is better than any other. It is not the source that matters; it is the information obtained from it. Previous research has shown, however, that acquiring information from external sources can be a powerful tool for achieving the organization-environment alignment. These sources might be more difficult to reach, less accessible and more time-consuming but in line with Lozada and Calantone (1997) we suggest that ongoing monitoring of external sources may help decision makers in deciding when an indepth search is warranted, thus helping them maximize limited resources and minimize uncertainty. Given limited resources, it might be wise to utilize personal/external sources - they usually have the advantage of speed, and may also provide advice and interpretation of information. Finally, when looking at how information is obtained, a combination of solicited and unsolicited information might be advantageous. Earlier research has shown that, if a preponderance of the information used is obtained on an unsolicited basis, performance can be questioned on the grounds that managers are not sufficiently active in seeking more of the important information they require. If the opposite proves true, performance could equally be questioned on the grounds that managers are not sufficiently sensitive to information other than that which they are actively seeking. Thus, the ideal would be to be both structured and flexible when searching for important information.

What, then, are the implications for further research? One interesting theme that emerged from this study was the fact that the combination of soft and hard information seemed to vary over time. Based on our knowledge, the terms "hard" and "soft" 
information are not widely used - nor do we know of any studies that have focused on the use of soft and hard information, how they interact, and their prevalence at different stages of decision-making processes. This is an interesting theme since we believe that these terms can add to our knowledge and further our understanding of the mechanisms of organizational decision making. Preferably, such a study should be undertaken utilizing a more nomothetic approach than was the case in this study. Another interesting theme emerged from the discussion part of this paper. There, several different and sometimes contradictory explanations were given in order to shed some light on our empirical findings when trying to relate them to existing literature. The question then arises as to which explanation is the most accurate, i.e. which explanation has the highest degree of explanatory power? Different explanations/theories can be analysed in terms of coverage and depth; for a discussion see Bunge (1967). Although conceptually appealing, we realize that such a study is very difficult to conduct empirically, although it would be of great value.

\section{Notes}

1. Perhaps the term "intelligence" should have been used instead of "information". Intelligence is, however, a fairly new term in the academic literature, and mixing the two might create confusion instead of facilitating communication and an exchange of views. Information in the present context should, however, be thought of as value-added, enabled and actionable.

2. For a discussion on differences between terms and concepts, see, for example, Zetterberg (1968).

Table I Uncertainty experienced, information used, and ways of obtaining information

Table I

Uncertainty experienced, information used, and ways of obtaining information

\begin{tabular}{|c|c|c|c|c|c|c|c|c|c|c|c|}
\hline & \multicolumn{3}{|c|}{ Uncertainty experienced } & \multicolumn{2}{|c|}{ Information used } & \multicolumn{3}{|c|}{ How information was obtained } & \multirow[b]{2}{*}{$\begin{array}{c}\text { Unsolicited } \\
\%\end{array}$} & \multirow[b]{2}{*}{$\begin{array}{c}\text { Directed } \\
\%\end{array}$} & \multirow[b]{2}{*}{$\begin{array}{c}\text { Undirected } \\
\%\end{array}$} \\
\hline & State & Effect & Response & $\begin{array}{c}\text { Hard } \\
\%\end{array}$ & $\begin{array}{c}\text { Soft } \\
\%\end{array}$ & $\begin{array}{c}\text { Solicited } \\
\%\end{array}$ & $\begin{array}{l}\text { Exp. } \\
\text { solicited } \\
\%\end{array}$ & $\begin{array}{l}\text { Org. } \\
\text { solicited } \\
\%\end{array}$ & & & \\
\hline \multicolumn{12}{|l|}{ Alpha } \\
\hline CEO & No & Yes & No & 0 & 100 & 60 & 60 & 0 & 40 & 13.3 & 26.7 \\
\hline Controller & No & Yes & No & $60-70$ & $30-40$ & 85 & 80 & 5 & 15 & 13 & 2 \\
\hline Board member & Yes & Yes & No & $60-65$ & $35-40$ & 50 & 15 & 35 & 50 & $15-20$ & $30-35$ \\
\hline Chair of the board & No & Yes & No & 50 & 50 & $80-85$ & $24-25$ & $56-60$ & $15-20$ & 0 & $15-20$ \\
\hline \multicolumn{12}{|l|}{ Beta } \\
\hline CEO & No & Yes & No & $70-80$ & $20-30$ & 90 & 18 & 72 & 10 & 10 & 0 \\
\hline Marketing director & No & Yes & No & 50 & 50 & 100 & 50 & 50 & 0 & 0 & 0 \\
\hline Business dev. dir. & No & Yes & No & 50 & 50 & $70-80$ & $49-56$ & $21-24$ & $20-30$ & $15-24$ & $4-6$ \\
\hline VP division C & No & Yes & No & 20 & 80 & 80 & $56-64$ & $16-24$ & 20 & 10 & 10 \\
\hline Director HR & No & No & No & 80 & 20 & 100 & 100 & 0 & 0 & 0 & 0 \\
\hline Key acc. manager & No & Yes & No & 80 & 20 & 50 & 45 & 5 & 50 & 0 & 50 \\
\hline \multicolumn{12}{|l|}{ Delta } \\
\hline CEo & No & No & No & 80 & 20 & 80 & 16 & 64 & 20 & 16 & 4 \\
\hline $\mathrm{VP}$ and $\mathrm{CFO}$ & No & No & No & 70 & 30 & 100 & $20-30$ & $70-80$ & 0 & 0 & 0 \\
\hline CEO (subsidiary) & No & No & No & 33 & 67 & 67 & 33.5 & 33.5 & 33 & 0 & 33 \\
\hline \multicolumn{12}{|l|}{ Gamma } \\
\hline CEO & No & Yes & No & $70-80$ & $20-30$ & 80 & 24 & 56 & 20 & 10 & 10 \\
\hline VP R\&D & No & No & No & 30 & 70 & 90 & 70 & 30 & 10 & 0 & 10 \\
\hline $\mathrm{CFO}$ & No & No & No & 75 & 25 & 75 & 37.5 & 37.5 & 25 & 18.75 & 6.25 \\
\hline VP legal affairs & Yes & Yes & No & 90 & 10 & 90 & 90 & 0 & 10 & 0 & 10 \\
\hline
\end{tabular}

Note: Respondents have been asked to indicate proportions, for example, between hard and soft

Table II Importance of different information sources for the decisions in question 
$\overline{\text { Table II }}$

Importance of different information sources for the decisions in question

\begin{tabular}{|c|c|c|c|c|c|}
\hline & Mean total & Mean alpha & Mean beta & Mean delta & Mean gamma \\
\hline \multicolumn{6}{|l|}{ External/impersonal sources } \\
\hline Business/financial publications & 2.18 & 3.00 & 2.00 & 1.33 & 2.25 \\
\hline Trade publications & 1.35 & 2.25 & 1.17 & 1.00 & 1.00 \\
\hline Technical/academic journals and books & 1.35 & 1.00 & 1.17 & 1.33 & 2.00 \\
\hline Purchased research reports & 1.59 & 1.00 & 1.50 & 1.00 & 2.75 \\
\hline Newspapers & 1.94 & 2.25 & 2.00 & 1.33 & 2.00 \\
\hline Trade shows & 1.82 & 1.25 & 1.17 & 2.67 & 2.75 \\
\hline Educational seminars & 1.65 & 1.00 & 2.00 & 1.33 & 2.00 \\
\hline The Internet (including databases) & 2.41 & 1.00 & 2.50 & 3.67 & 2.75 \\
\hline Industry-specific statistics & 2.88 & 3.75 & 2.17 & 2.67 & 3.25 \\
\hline \multicolumn{6}{|l|}{ External/personal sources } \\
\hline Bankers and financial advisers & 2.24 & 2.75 & 1.17 & 1.33 & 4.00 \\
\hline Customers & 3.53 & 5.00 & 4.50 & 2.33 & 1.50 \\
\hline Suppliers & 2.29 & 4.25 & 2.00 & 1.33 & 1.50 \\
\hline Consultants & 2.00 & 1.50 & 2.00 & 1.33 & 3.00 \\
\hline Accountants and lawyers & 2.24 & 3.00 & 1.33 & 3.00 & 2.25 \\
\hline Competitors & 2.76 & 3.75 & 1.83 & 2.67 & 3.25 \\
\hline Friends & 1.59 & 1.25 & 2.00 & 1.00 & 1.75 \\
\hline Outside business and prof. associates & 2.47 & 3.00 & 1.83 & 1.33 & 3.75 \\
\hline Friends and chance encounters & 1.12 & 1.00 & 1.00 & 1.00 & 1.50 \\
\hline \multicolumn{6}{|l|}{ Internal/personal sources } \\
\hline Superiors (line relationship) & 2.71 & 1.25 & 2.67 & 4.00 & 3.25 \\
\hline Subordinates (line relationship) & 3.71 & 4.25 & 3.83 & 3.00 & 3.50 \\
\hline Others (horizontal relationship) & 3.18 & 1.75 & 4.00 & 2.33 & 4.00 \\
\hline \multicolumn{6}{|l|}{ Internal/impersonal sources } \\
\hline Performance reports (acc., fin., prod.) & 3.53 & 3.00 & 3.00 & 4.00 & 4.50 \\
\hline Salesmen call reports & 3.18 & 2.50 & 3.83 & 3.33 & 2.75 \\
\hline Intelligence- or information-system & 2.41 & 2.00 & 2.50 & 2.00 & 3.00 \\
\hline Reports or notes from internal meetings & 3.12 & 2.50 & 3.17 & 4.00 & 3.00 \\
\hline
\end{tabular}

Notes: A 5-point Likert-scale was used (1: lowest value; 5: highest value)

\section{References}

Aguilar, F.J. (1967), Scanning the Business Environment, Macmillan, New York, NY, .

Aldrich, H.E., Mindlin, S. (1978), "Uncertainty and dependence: two perspectives on environment", in Karpik, L. (Eds),Organizations and Environment, Sage Publications, Beverly Hills, CA, pp.149-70.

Bunge, M. (1967), Scientific Research II - The Search for Truth, Springer-Verlag, Berlin, .

Choo, C.W. (1996), "The knowing organization: how organizations use information to construct meaning, create knowledge and make decisions", International Journal of Information Management, Vol. 16 No.5, pp.329-40.

Cyert, R.M., March, J.G. (1963), A Behavioral Theory of the Firm, Prentice-Hall, Englewood Cliffs, NJ, .

Daft, R.L., Sormunen, J., Parks, D. (1988), "Chief executive scanning, environmental characteristics, and company performance: an empirical study", Strategic Management Journal, Vol. 9 No.2, pp.123-39.

Duncan, R.B. (1972), "Characteristics of organizational environments and perceived environmental uncertainty", Administrative Science Quarterly, Vol. 17 No.3, pp.313-27.

Dutton, J.E., Jackson, S.E. (1987), "Categorizing strategic issues: links to organizational action", Academy of Management Review, Vol. 12 No.1, pp.76-90. 
Eaton, J.J., Bawden, D. (1991), "What kind of resource is information?", International Journal of Information Management, Vol. 11 No.2, pp.156-65.

Elenkov, D.S. (1997), "Strategic uncertainty and environmental scanning: the case for institutional influences on scanning behavior", Strategic Management Journal, Vol. 18 No.4, pp.287-302.

Fahey, L., Narayanan, V.K. (1986), Macroenvironmental Analysis for Strategic Management, West Publishing Company, St Paul, MN, .

Frishammar, J. (2002), "Characteristics in information-processing approaches", International Journal of Information Management, Vol. 22 No.2, pp.143-56.

Galbraith, J.R. (1973), Designing Complex Organizations, Addison-Wesley, Reading, MA, .

Galtung, J. (1967), Theory and Methods of Social Research, George Allen \& Unwin, London, .

Ghoshal, S. (1988), "Environmental scanning in Korean firms: organizational isomorphism in action", Journal of International Business Studies, Vol. 28 No.1, pp.69-86.

Häckner, E. (1988), "Strategic development and information use", Scandinavian Journal of Management, Vol. 4 No.1, pp.4561 .

Hambrick, D.C. (1982), "Environmental scanning and organizational strategy", Strategic Management Journal, Vol. 3 No.2, pp.159-74.

Hendry, J. (2000), "Strategic decision making, discourse, and strategy as social practice", Journal of Management Studies, Vol. 37 No.7, pp.955-77.

Johnson, G., Scholes, K. (1999), Exploring Corporate Strategy, Prentice-Hall, Hemel Hempstead, .

Kaye, D. (1995), "The nature of information", Library Review, Vol. 44 No.8, pp.37-48.

Keegan, W.J. (1974), "Multinational scanning: a study of the information sources utilized by headquarters' executives in multinational companies", Administrative Science Quarterly, Vol. 19 No.3, pp.411-21.

Laroche, H. (1995), "From decision to action in organizations: decision making as social representation", Organization Science, Vol. 6 No.1, pp.62-75.

Lord, R.G., Maher, K.J. (1990), "Alternative information-processing models and their implications for theory, research, and practice", Academy of Management Review, Vol. 15 No.1, pp.9-28.

Lozada, H., Calantone, R. (1997), "Scanning behavior and environmental variation in the formulation of strategic responses to change", Journal of Business \& Industrial Marketing, Vol. 11 No.1, pp.17-42.

March, J.G., Simon, H.A. (1958), Organizations, Wiley, New York, NY, .

Milliken, F. (1987), "Three types of perceived uncertainty about the environment: state, effect, and response uncertainty", Academy of Management Review, Vol. 12 No.1, pp.133-43.

Mintzberg, H. (1975), "The manager's job: folklore and fact", Harvard Business Review, Vol. 53 No.4, pp.49-61.

Mintzberg, H., Raisinghani, D., Theoret, A. (1976), "The structure of 'unstructured' decision processes", Administrative Science Quarterly, Vol. 21 No.2, pp.246-75.

Sawyerr, O.O., Ebrahimi, B.P., Thibodeaux, M.S. (2000), "Executive environmental scanning, information source utilization, and firm performance", Journal of Applied Management Studies, Vol. 9 No.1, pp.95-116.

Schoemaker, P.J. (1993), "Strategic decisions in organizations: rational and behavioural views", Journal of Management 
Studies, Vol. 30 No.1, pp.107-26.

Thomas, P.S. (1980), "Environmental scanning - the state-of-the-art", Long Range Planning, Vol. 13 No.2, pp.20-8.

Tushman, M.L., Nadler, D.A. (1978), "Information processing as an integrating concept in organizational design", Academy of Management Review, Vol. 3 No.3, pp.613-24.

Weick, K.E. (1995), Sensemaking in Organizations, Sage Publications, Thousand Oaks, CA, .

Weick, K.E. (2001), Making Sense of the Organization, Blackwell Business, Oxford, .

Yin, R.K. (1994), Case Study Research - Design and Methods, Sage Publications, Thousand Oaks, CA, .

Zetterberg, H.L. (1968), On Theory and Verification in Sociology, Wretmans Boktryckeri AB, Uppsala, . 